\title{
PENGARUH MODEL PEMBELAJARAN KOOPERATIF TIPE THINK- PAIR-SHARE (TPS) TERHADAP HASIL BELAJAR SISWA PADA MATERI MENGGUNAKAN ALAT UKUR
}

\author{
Frans Tinus ${ }^{1}$, Debora $^{2}$, Wiyogo $^{3}$ \\ ${ }^{1,2,3}$ Fakultas Keguruan dan Ilmu Pendidikan, Universitas Palangka Raya \\ E-mail: franstinusduluni@gmail.com
}

\begin{abstract}
This study aims to determine the effect of Think-Pair-Share (TPS) learning model on student learning outcomes in using measuring instruments on pneumatic systems lesson. The research methods used are experimental. The sampling technique is random sampling, where the first sample of class X TBSM with the number of students is 32 people, which is taught by the TPS and the second sample class X TBSM with a total of 26 people taught by conventional models, instruments used is a multiple choice test which amounts to 40 questions before the test questions are used to test the validity, reliability, differentiation, and level of difficulty of the questions. The results showed that $\mathrm{H}_{0}$ is rejected and $\mathrm{H}_{1}$ is accepted, which shows that there are influences of student learning outcomes taught using cooperative learning type TPS with student learning outcomes.
\end{abstract}

Keywords: think-pair-share, learning outcomes

\section{PENDAHULUAN}

Sekolah Menengah Kejuruan (SMK) merupakan salah satu penyelenggara pendidikan, dimana memiliki tujuan untuk mempersiapkan peserta didik untuk siap kerja. SMK dituntut untuk dapat menciptakan lulusan yang mempunyai keahlian, yang nantinya dapat bersaing dalam dunia kerja. Hal ini telah ditegaskan dalam Undang-Undang Sistem Pendidikan Nasional (UUSPN) pasal 3 mengenai tujuan pendidikan dan penjelasan pasal 15 menyebutkan bahwa pendidikan menengah kejuruan bertujuan untuk menyiapkan peserta didik terutama untuk bekerja dalam bidang tertentu. Tujuan tersebut dapat dijabarkan lagi oleh Dikmenjur (2003) menjadi tujuan umum dan tujuan khusus. Tujuan umum, sebagai dari sistem pendidikan menengah kejuruan SMK bertujuan: (1) meningkatkan keimanan dan ketaqwaan, (2) mengembangkan potensi peserta didik agar menjadi warga negara yang berakhlak mulia dan cerdas, (3) mengembangkan peserta didik agar memiliki wawasan kebangsaan, memahami dan menghargai, (4) mengembangkan potensi peserta didik agar memilik kepedulian terhadap lingkungan hidup. Sedangkan tujuan khusus SMK bertujuan, (1) menyiapkan peserta didik agar menajdi manusia produktif, (2) menyiapkan peserta didik untuk mampu memilih karir dalam berkompetensi, (3) membekali peserta didik dengan pengatahuan, teknologi dan seni agar mampu mengembangkan diri, dan (4) membekali peserta didik dengan kompetensi-kompetensi yang sesuai dengan bidang keahlian.

Berdasarkan hasil observasi di SMK Karsa Mulya kelas X Teknik Bisnis Sepeda Motor (TBSM) khusus pada mata pelajaran menggunakan alat ukur sistem pneumatik memiliki jumlah siswa sebanyak 32 orang siswa, dari 32 orang siswa terdapat 12 orang yang tidak tuntas dan 20 orang tuntas (hanya $75 \%$ tuntas dan $25 \%$ tidak tuntas dalam ulangan semester ganjil dalam mata pelajaran Menggunakan alat ukur pada sistem pneumatik dengan nilai Kriteria Ketuntasan Minimum (KKM) 70 untuk produktif.

Faktor penyebab rendahnya nilai hasil semester genap ialah: (1) rendahnya hasil belajar siswa di kelas X TBSM dari 32 siswa, sebagian siswa belum mencapai kriteria ketuntasan minimum pada mata pelajaran menggunakan alat ukur pada sistem pneumatik, (2) siswa mengalami kesulitan untuk memahami materi pembelajaran, (3) metode pembelajaran yang digunakan guru belum maksimal untuk meningkatkan motivasi belajar peserta didik sehingga siswa cenderung merasa bosan. Berdasarkan permasalahan diatas untuk menyelesaikan hal tersebut maka menurut peneliti perlu menggunakan model yang efektif dan efisien untuk membantu pemahaman siswa. salah satu upaya yang dapat dilakukan untuk memecahkan permasalahan-permasalahan tersebut adalah dengan pemilihan model belajar yang tepat sehingga proses belajar di kelas terasa sangat menyenangkan. Dalam suatu proses belajar mengajar, dua unsur yang amat penting adalah metode mengajar dan media pembelajaran. 
Pemilihan model pembelajaran tertentu mempengaruhi jenis media pembelajaran yang sesuai, meskipun masih banyak aspek lain yang harus diperhatikan, missal tujuan pembelajaran, lingkungan, dan fasilitas pendukung. Penerapan model TPS diharapkan siswa dapat mengembangkan keterampilan berfikir dan menjawab dalam komunikasi antara satu dengan yang lain, serta bekerja saling membantu dalam kelompok kecil. Hal ini sesuai dengan pengertian dari model pembelajaran TPS itu sendiri, TPS adalah pembelajaran yang memberi siswa kesempatan untuk bekerja sendiri dan bekerjasama dengan orang lain. Dalam hal ini, guru sangat berperan penting untuk membimbing siswa melakukan diskusi, sehingga terciptanya suasana belajar yang hidup, aktif, kreatif, efektif dan menyenangkan.

\section{METODE}

Penelitian ini menggunakan metode penelitian kuantitatif karena data penelitian berupa angkaangka dan analisis menggunakan statistik, dan tujuan dari penelitian ini adalah untuk meneliti pengaruh antar variabel atau sebab-akibat. Berdasarkan tujuan penelitian yang telah diuraikan maka jenis penelitian ini adalah jenis penelitian eksperimen. Menurut Sugiyono (2011:107), penelitian eksperimen dapat diartikan sebagai metode penelitian yang digunakan untuk mencari pengaruh perlakuan tertentu terhadap yang lain di dalam kondisi yang terkendalikan.

Penelitian ini dilakukan pada siswa kelas X TBSM di SMK Karsa Mulya Palangka Raya. Kelas yang diteliti terdiri dari dua kelas, yaitu kelas eksperimen dan kelas kontrol. Untuk menentukan kelas tersebut, pemilihan sampel penelitian dilakukan secara acak, maka didapat sampel untuk kelas eksperimen adalah kelas X TBSM 1 dengan jumlah 32 siswa dan kelas kontrol adalah kelas X TBSM 2 dengan jumlah 26 siswa.

Pada kelas eksperimen diberi perlakuan pembelajaran kooperatif tipe TPS, pada materi menggunakan alat ukur pada sistem pneumatik. pertemuan dilakukan 3 kali tatap muka dan 1 kali praktikum. Untuk kelas kontrol kegiatan pembelajaran dilakukan seperti bisa yaitu dengan model konvensional pada materi menggunakan alat ukur pada sistem pneumatik. pertemuan dilakukan 3 kali tatap muka dan 1 kali praktikum. Di akhir kegiatan, kelas eksperimen dan kelas kontrol diberikan posttest tes hasil belajar untuk mendapatkan nilai kognitif. Untuk nilai afektif dan psikomotor didapat pada proses pembelajaran 4 kali pertemuan dengan melakukan pengamatan.

\section{HASIL DAN DISKUSI}

Data hasil belajar siswa dari ranah kognitif, afektif dan psikomotor akan digabungkan sebagai hasil belajar siswa. Pembagian ranah tersebut adalah hasil belajar kognitif sebesar 50\%, afektif 20\% dan psikomotor $30 \%$. Berikut deskripsi data dari hasil belajar siswa kelas eksperimen dan kelas kontrol dapat dilihat pada Tabel 1.

Tabel 1. Data Tes Hasil Belajar Akhir Kelas Eksperimen dan Kelas Kontrol

\begin{tabular}{cccccccc}
\hline Kelas & $\mathrm{N}$ & Skor Total & $\mathrm{X}_{\min }$ & $\mathrm{X}_{\max }$ & Rerata & Varians & Standar Deviasi \\
\hline Eksperimen & 32 & 2733 & 79 & 92 & 85 & 16,38 & 4 \\
Kontrol & 26 & 1808 & 60 & 77 & 70 & 15,14 & 3,90 \\
\hline
\end{tabular}

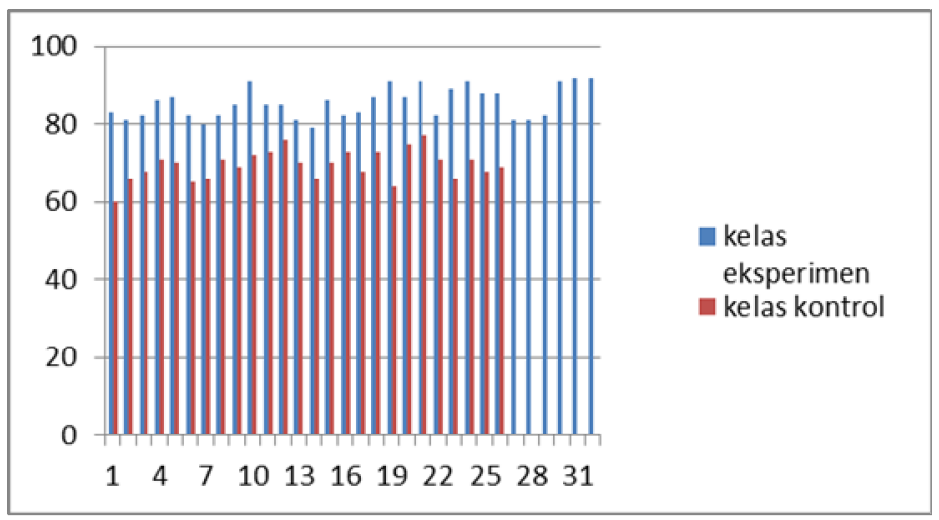

Gambar 1. Diagram Skor Hasil Belajar Akhir Siswa Kelas Eksperimen dan Kelas Kontrol 
Berdasarkan Tabel 1 terlihat bahwa terdapat perbedaan hasil belajar pada kelas eksperimen dan kelas kontrol. Pada kelas eksperimen, dengan jumlah total siswa 32 orang, diperoleh skor total 2733 dan rerata 85. Pada kelas kontrol, dengan jumlah siswa 26 orang, diperoleh skor total 1808 dan rerata 70. Skor tertinggi pada kelas eksperimen adalah 92 dan skor terendah 79. Skor tertinggi pada kelas kontrol adalah 77 dan skor terendahnya 60.

Berdasarkan Gambar 1 terlihat bahwa hasil belajar siswa pada kelas eksperimen yang diberi perlakuan dengan pembelajaran kooperatif tipe TPS memiliki hasil belajar lebih tinggi dibandingkan kelas kontrol yang diberikan perlakuan pembelajaran dengan model konvensional.

Hasil belajar siswa kelas eksperimen dan kelas kontrol selanjutnya akan dianalisis dan ditafsirkan untuk mengetahui pengaruh pembelajaran kooperatif tipe TPS terhadap hasil belajar siswa. Berdasarkan teknik analisis data, dilakukan uji statistik untuk menguji hipotesis yang diajukan, diperoleh nilai $t_{\text {hitung }}$ sebesar $=3,60$. Dari hasil perhitungan tersebut dibandingkan dengan nilai $t_{\text {tabel }}$ yaitu $=3,60>2,03$.

\section{SIMPULAN}

Berdasarkan hasil analisis data, perhitungan nilai hasil belajar siswa setelah melaksanakan penelitian eksperimen diperoleh nilai $t_{\text {hitung }}$ sebesar $=3,60$ dari hasil perhitungan tersebut dibandingkan dengan nilai $\mathrm{t}_{\text {tabel }}$ yaitu $=3,60>2,03$, maka jawaban hipotesis penelitian yang diperoleh yaitu $\mathrm{H}_{1}$ diterima. Berdasarkan hasil analisis data yang telah diuraikan diatas, maka dapat disimpulkan bahwa terdapat pengaruh model pembelajaran TPS terhadap hasil belajar siswa pada materi menggunakan alat ukur pada sistem pneumatik di kelas X TBSM SMK Karsa Mulya Palangka Raya.

\section{DAFTAR RUJUKAN}

Depdiknas. (2003). Sistem Pendidikan Nasional. Bandung: Citra Buana.

Sugiyono. (2011). Metode Penelitian Kuantitaf Kualitatif dan R\&D. Bandung: Alfabeta 